\begin{tabular}{|c|c|c|}
\hline & Mansoura University & 0 \\
Faculty of Engineering & $=0$ & 0 \\
\hline
\end{tabular}

\title{
THE ROLE OF CYCLING AND WALKABILITY ON REVITALIZING THE HISTORIC URBAN AREAS IN EGYPT CASE STUDY: EL GALAA STREET - DAMIETTA CITY

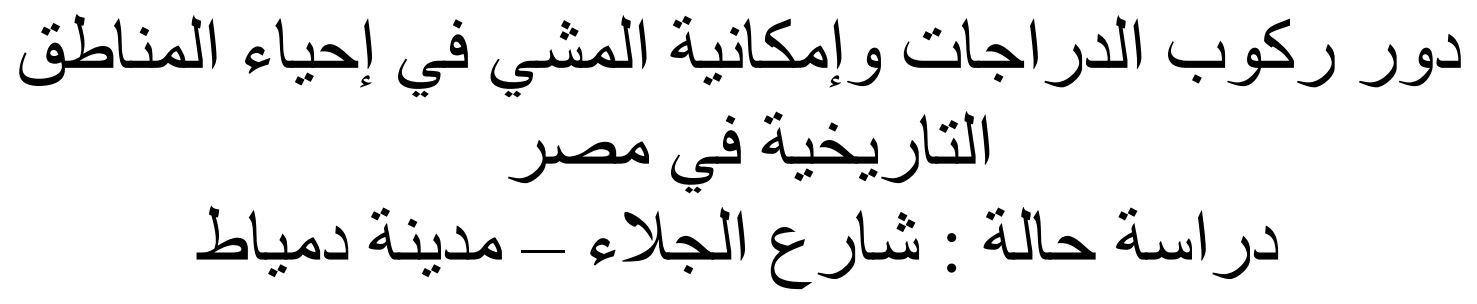

Heba Mohammed Hafez El Saied, Lamis Saad El Din El Gezawi and Nanees Abd El Hamid El Sayad

\section{KEYWORDS: \\ Historic Urban Areas, Cycling and Walkability, Revitalization, El Galaa street, Damietta city.}

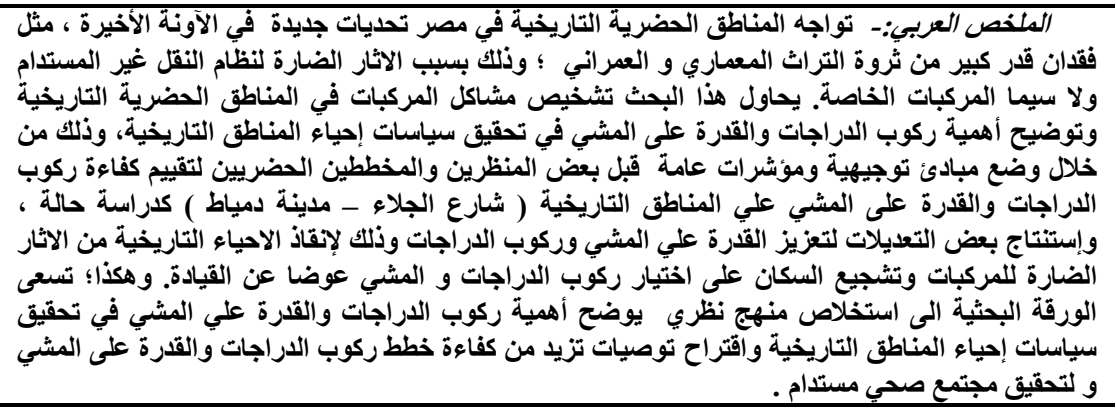

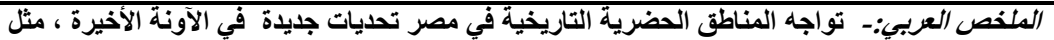

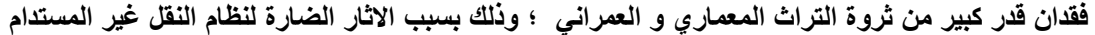

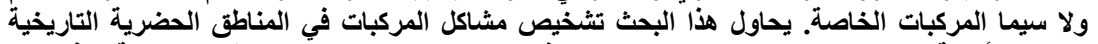

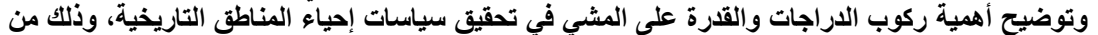

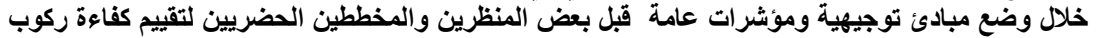

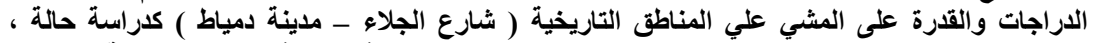

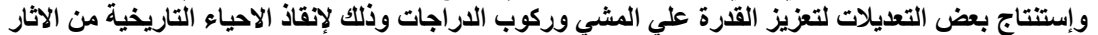

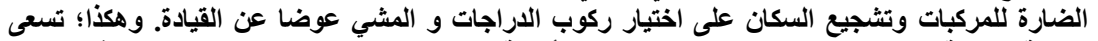

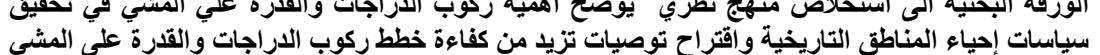

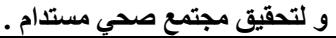

Abstract - Egypt's historic urban areas face new challenges in recent times, such as the loss of its rich architectural and urban heritage due to the adverse effects of the unsustainable transportation system, particularly private vehicles. This research attempts to diagnose vehicle problems in historic urban 2018

Received: 3 July 2018 - Revised: 13 August 2018 - Accepted: 8 September

Heba Mohamed Hafez El Saied, Demonstrator, Dep of Architectural Engineering, Faculty of Engineering Mansoura University (e-mail: archheba1992@gmail.com)

Lamis Saad El Din El Gezawi, Associated Professor in Architecture- Dep, Faculty of Engineering, Mansoura University (e-mail: dr-lamis@yahoo.com)

Nanees Abd El Hamid El Sayad, Lecturer, Architecture- Dep, Mansoura University(e-mail: arch_n_elsayad@yahoo.com.au). areas, and explain the importance of cycling and walkability in realization of policies to revive historic areas. This can be done through the development of guidelines and general indicators by some urban theorists and planners to assess the efficiency of cycling and the ability to walk in historic areas (Al-Galaa Street, Damietta City) as a case study and to make some adjustments to enhance walkability and cycling to save historic urban areas from the harmful effects of vehicles and encourage the residents to choose cycling and walkability over driving. The paper seeks to draw a theoretical approach that demonstrates the importance of cycling and walkability in the realization of policies to revive historical areas and propose recommendations that increase the efficiency of cycling training plans and walkability and to achieve a healthy and sustainable society 


\section{INTRODUCTION}

$\mathrm{W}$ alkability was essential in cities before the vehicles era. Streets of the preindustrial city were by necessity walkable, since everyone depended upon ready access by foot or slow-moving wagon or carriage to access to work and marketplaces density of dwellings had to be relatively high, and everything had to be connected by a continuous pedestrian path network. [1]. In the meanwhile, the disadvantages of greater car dependence affect our personality and health from the very beginning. [2] The increased awareness of the many negative implications of current vehicles dependence patterns had helped to ensure that much more official recognition is now being given to the many health advantages of cycling and walking, in terms of both public and individual health. Now a growing number of American and European cities are getting rid of cars in certain urban context through fines, better design, and new apps. [3]. Cycling and Walkability affects the Revitalization of the historic urban areas and architectural values, as in old cities, pedestrians have time and leisure to enjoy and study the details of buildings and urban spaces. During driving a car, we miss out the opportunity to grasp details of a valuable architecture and to see people and share in the public activities. Based on that, the historic urban of most of 20th century districts has been deteriorating throughout the years due to the harmful effects of the different transportation modes, congestion and traffic problems. In order to overcome this negative impact, people should be encouraged to choose public transportation, walking and cycling over driving, where sustainable mobility has low environmental impact, social and recreational value and promotes mental and physical health. Especially in historic urban areas which raise the cultural historic awareness of the residents. Based on that the paper will discuss how we can utilize cycling and walkability as a tool to revitalize historic urban areas. Historical urban spaces will be the focus of this study. The research will present the case study of "El Galaa street, Damietta city", in which the cycling and walkability strategies are used in the revitalization proposal.

\section{STUDY OBJECTIVES}

- Studying cycling and walkability concept and needs.

- Redevelopment and strengthen the historic urban of the city through cycling and walkability concept.

- Revitalization of cultural, environmental, natural and historical resources.

- Conducted Criteria and indicators that effect the cycling and walkability in urban context.

\section{METHODOLOGY:}

The whole study is divided into three stages: The first is data collection to understand what walkability is, the theoretical framework of cycling and walkability requirements and indicators, meaning of historic areas, urban Revitalization and The link between "cycling \& walkability" requirements, indicators and urban Revitalization of historic urban areas.
The second is about the case study: El Galaa street, Damietta city; its history, the existing situation analysis by an Evaluation framework of Indicators for successful walkable \& cycling districts. The third stage will be consisting of several steps including analyzing the existing situation, proposing design changes using needs and indicators that effect cycling and walkability as a tool to Revitalize historical urban areas.

\section{A THEORETICAL BACKGROUND ON THE CONCEPT OF "CYCLING AND WALKABILITY" AND ITS RELATION TO THE REVITALIZATION OF HISTORIC URBAN AREAS:"}

\section{A. Walkability: Definitions and Needs}

Walkability is a measure of how friendly an area is to walking." Walkability" and ,walkable"e are terms that have become common in the fields of engineering, planning and health, because walking is widely recognized as having benefits for the environment as well as social, health and economic well-being of a society. The term „,walkability"e was defined by (Abley 2005) [4], as ,the extent to which the built environment is walking friendly".

\section{B. Cycling and Walkability needs:}

According to Jeff Speck [5], "Walkability is a useful way to assess the characteristics of an area or a route, although it can be subjective". Also he explained in 2012 in his General Theory of walkability walking has to satisfy four main conditions: it must be useful, safe, comfortable, and interesting. Each of those qualities are essential and none alone is sufficient. Useful means that most aspects of daily life are located close at hand and organized in a way that walking serves them well. Safe means that the street has been designed to give pedestrians a gating chance against being hit by automobiles; they must not only be safe but feel safe, which is even tougher to satisfy. Comfortable means that buildings and landscape shape urban streets into outdoor living rooms, in contrast to wide- open spaces, which usually fail to attract pedestrians. Interesting means that sidewalks are lined by unique buildings with friendly faces and that signs of humanity abound. Hence, walkability requirements are based on five main needs; (Attractiveness, Accessibility \& safety, environmental and comfortable walk, design and function, economic and useful walk) as shown in figure 1. Moreover, based on Kafafy, (2014) [6], there are four types of pedestrian zones:

1. Modified street zone: one block is closed for pedestrianonly use.

2. Plaza: several blocks are closed but the cross-streets stay open to all traffic.

3. Continuous: several blocks and the cross-streets are closed. 


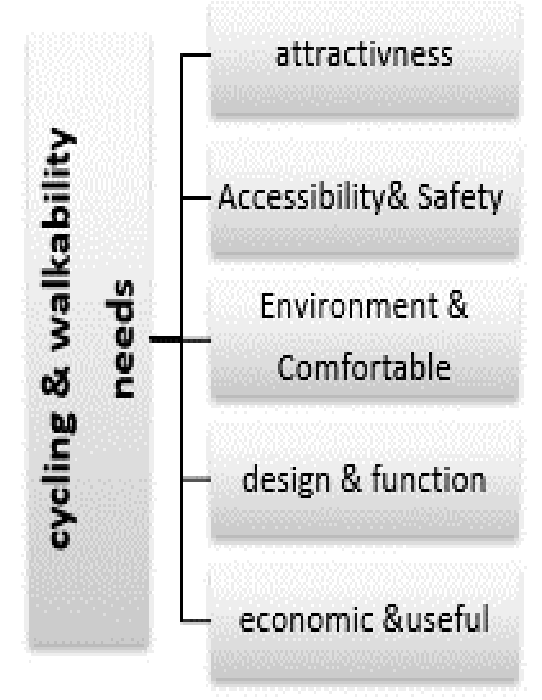

Fig. 1. Walkability needs (Ref: Researcher)

\section{Indicators for Enhancing Cycling \& Walkability:}

Based on multilevel theoretical model theories by different theorists, architects and urban planners there are many indicators and guidelines for enhancing walkability in old districts and modern sprawls all over the world. The following table (1) investigates different guidelines and indicators by five different analyzers in the developed and developing countries, such as Hugh Mcclintock [7] in his book: Planning for cycling: principles practice and solutions for urban planners, provides different methodologies and guidelines from different countries that are considered top ranked countries in enhancing walkability and cycling decades ago, and Jeff Speck the American urban planner in his book" Walkable City: How Downtown Can Save America, One Step at a Time. [8], which is tackling the general theory for walkability in American cities, and MARIELA A. ALFONZO, [9] who is a doctoral student in the Department of Planning, Policy, and Design at the University of California, Irvine, offers a hierarchy of walkability needs that operates and organizes five levels of needs and presents them as an antecedent within the walking decision-making process. While in European countries there is Jan Ghel the Danish urban planner in his very popular book: cities for people [10] which studies walkability from the human dimensiones point of view In the meanwhile, in the developing countries, El Serafy [11] who is a doctoral student in the Department of Architecture, Cairo university, built a tool based on analyzing different factors of mobility affecting the quality of life in urban spaces, and the guidelines for applying concept of cycling \& walkability based on the analysis of different action plans that were adopted and implanted in different historic cities concerning sustainable mobility management. As shown in table (1).
TABLE. 1

INDICATORS FOR ENHANCING CYCLING \& WALKABILITY (REF: RESEARCHER)

\begin{tabular}{||l||l}
\multicolumn{1}{|c}{ Indicators for successful } \\
walkable\& cycling districts \\
\hline
\end{tabular}

\section{The Effects of Vehicles on Cycling and Walkability}

The Reason behind Increasing Car Ownership in Egypt is the lack of public transport coverage and low service levels and inter-modal transfer, moreover the lack of proper traffic management and efficiency [12]. The Inadequate facilities for public transport, is considered one of the pivotal problems within the Egyptian context, as the levels of public transportation are depressing for most of the travellers, where it's inhumanly very congested, slow, lacking safety measurements, do not cover most of the regions within the 
city. Not to mention that, there is almost absence of cycling lanes and inadequate infra-structure for cycling and sidewalks, this makes cyclists and pedestrians neither safe nor satisfied. Moreover, pedestrians are discouraged to choose walking and cycling as a usable alternative, where most of the sidewalks are not leveled, with broken pavement that causes many injuries for pedestrians and cyclists. Yet, despite the increasing understanding of threats associated with car dependence globally, today car ownership remains in continuous increase globally, with projections of largest markets in developing countries. [13].

\section{E- The Effect of Vehicles on Air Quality and Health}

Egyptian urban settlements especially, are characterized by high air pollution levels, which dismays pedestrian users. The Cairo Air Improvement Project (CAIP), a Source-AttributionStudy (SAS) was conducted between 1997 and 2004 to identify the contribution of various sources to air pollution in Egypt, revealed that vehicle exhaust accounted for 32\% of air pollution indicated by particle matter in air [14].Yet, according to the Egypt Second National Communication for the United Nations Framework Convention for Climate Change (UNFCCC), 26\% of all GHG emissions from fuel combustion (the major source) is attributed to transportation alone [15].Adding on that, one of the most pivotal problems of walking and cycling in Egypt is parking, especially free one. Based on (Soup,2005) parking worsens air quality, speeds global warming, increases energy consumption, raises the cost of housing, decreases public revenue, undermines public transportation, increases traffic congestion, damages the quality of the public realm, escalates suburban sprawl, threatens historic buildings, weakens social capital, and worsens public health. [16].

\section{HISTORIC URBAN AREAS}

The Planning (Listed Buildings and Conservation Areas) Act 1990 defined historic urban area as "Area of special architectural or historic interest of the character ".

The ICOMOS Brazilian committee, Itaipava, July 1987 defined it as "Those spaces where manifold evidence of the city's cultural production concentration". They are comprising the natural and the built environment and the everyday living experiences of their inhabitants. These areas have many values of remote or recent origin and permanently undergoing a dynamic process of successive transformations.

\section{A. Historic Urban Areas Classification}

Historic urban areas can be classified according to their values as follows

Heritage value, Architectural value, Aesthetic value, Environment value and Economic and Functional value as shown in figure 2.

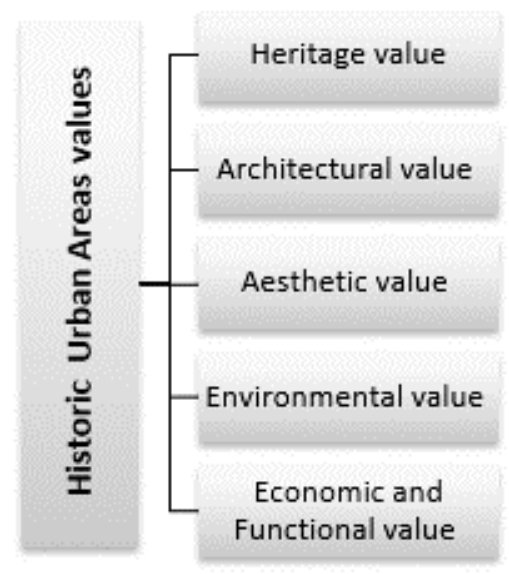

Fig. 2.historic urban areas values (Ref: Researcher)

1. Heritage value acquired during long decades. This value indicates to the age which urban heritage sites and their building were built or indicates to a historical, national or specific event.

2. Architectural value represents in the style that the architecture building or monument that has been built with at that time. It could be a new style or a way of building, or built by a famous architect, giving both a character and a landmark to the whole site. [17]

3. Aesthetic value that has been produced from urban heritage sites due to the aesthetics of the past, and being as antiques because they have a scarcity value. Their building facades adorned with sculpture and ornaments, showing the archaic skills of masons and carvers. These sites have picturesque qualities and redolent of a period of genuine craftsmanship and individuality that currently have been lost. [18]

4. Environmental value has been resulted from urban heritage sites that represented five elements of urban images (paths, nodes, edges, districts and landmarks), each of these elements represents visual and environmental image of the city. [19]

5. Economic and Functional value [20]:

a. The economic value when using these sites positively by playing a role in the daily economic life and linking it to the development process.

b. Functional value:

Heritage site was built to do a specific function, doing its original function such mosques and churches value of the building is high but if a building become as a monument only and functional value is decreasing.

\section{URBAN REVITALIZATION OF HISTORIC URBAN AREAS}

The process of revitalization in an area or a part of the city includes improving the physical and economic aspects of buildings and urban spaces. Physical revitalization is a shortterm strategy intended to encourage long-term economic 
growth. Physical revitalization believed to improve the physical condition (including public spaces) of the city, but not in a long term process [21]. It is necessary to improve an economic activity which by considering the social, cultural and environmental aspects of the locality [22]. A city is a complex organism and the activities are complex as well, thus, economic revitalization do not solely depend entirely on physical aspects alone, several other aspects need to be addressed as follows [23]

\section{1- Physical Revitalization}

Helps to initiate the physical activities of revitalization to be carried out in stages, including the development and improvement of the quality and physical condition of buildings, green open space, connecting the urban systems, and street furniture. Pedestrian and bicycle network, Entries, Automatic traffic networks, elements of vacuum brushes, Open and Green Area Network

\section{2- Economic Revitalization}

Physical improvement of places including the areas that targeted for short-term economic development as well as the informal and formal economic activities either local or international economic development. In the vitality context of revitalization, it needs to be developed into multi-functional activities, mixed uses that include physical, economic, and social activities.

\section{3- Social / institutional revitalization}

The success of revitalizing an area will be measurable if the element used to create an interesting environment is tangible and transparent and not solely on creating a beautiful place. These activities should have a positive impact that helps to improve the dynamics and social life of the community.

\section{A. The linkage between "cycling \& walkability" needs indicators and Revitalization of historic urban areas [24]:}

The efforts to increase the vitality of the historic urban areas can be managed through an arrangement of "cycling \& walkability" needs as following:

\section{1-Attractiveness}

The attraction element is a region generator that is expected by the urban governance to generate vitality The historic area must be recognizable and have a character as well as an identity of its own [25], [26].

- Conservation on the main monuments and activities that is accessible with a strong linkage for image representations.

- Heritage buildings in the area can also be used as landmarks.
- Improving public spaces, improves the environment of the area, reduces air and noise pollution, provides the population with an enjoyable environment and allows for a variety of activities such as children's play areas, picnic area, and celebrations.

\section{2- Accessibility and Safety}

- The accessibility to all areas can be achieved by reducing traffic congestions and the continuous physical networks within the urban systems, vehicles, buses, and service. Vehicles, which must be located at external points in multiple entrances of the historic urban area, and not allowed to enter the area [27].

- Safety of pedestrians related with many issues, such as traffic and street crime, handicapped needs, placement and length of crosswalks, traffic speeds, pedestrian and traffic control signs and signals, sidewalk width, sidewalk condition, path surveillance and night lighting. [28].

\section{3-Environment \& Comfortable:}

- Cleaning and repairing the external streets of value.

- Improving the general appearance of the area, dealing with the negative effects of traffic [29].

- Aesthetic and environmental qualities are required to provide comfort through the arrangement of urban elements with regards to proportion, scale and size, rhythm, sequence, pattern and texture, continuity, dominance and volume [30].

- Improving roads, finding parking pedestrian corridors, urban infrastructure, lighting, public signs and placing street seats, and relaxation space covered with good and simplified exterior brushes.

\section{4- Design \& function: [31].}

- Removing ugly objects such as filth and dirt from old buildings, so that they can be repaired, rehabilitated.

- Improving the facades of the shops and the main buildings with Optimizing human dimension.

- Customize lanes and places to wait for bikes.

- Continuity of sidewalks and other pedestrian paths without significant barriers

Figure 5. The urban fabric of El Galaa street with the three intersections (Ref: [36])

\section{5- Economic \& useful [32]:}

- Integration of different types of housing, mixed uses and shopping areas throughout the day with continuous observed activities to create a rich and lively environment in the historic areas.

Hence, the linkage between Revitalization of historic urban areas and "cycling and walkability", needs and indicators, where it can benefit from opportunities to improve the physical, Economical and Social environment of historic urban areas. As following in table (2) 
TABLE. 2.

THE LINKAGE BETWEEN "CYCLING \& WALKABILITY" NEEDS, INDICATORS AND REVITALIZATION OF HISTORIC URBAN AREAS:

(REF: RESEARCHER)

\begin{tabular}{|c|c|c|c|c|c|}
\hline \multirow[b]{2}{*}{ 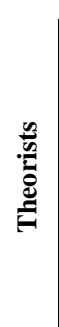 } & \multirow[b]{2}{*}{ | } & (REF: RESEARCHER) & \multicolumn{3}{|c|}{$\begin{array}{c}\text { Urban } \\
\text { Revitalization } \\
\text { aspects }\end{array}$} \\
\hline & & $\begin{array}{l}\text { Indicators for successful walkable \& } \\
\text { cycling districts }\end{array}$ & 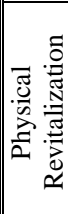 & 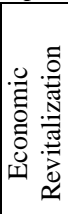 & 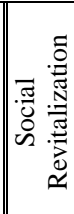 \\
\hline \multirow{10}{*}{ 范 } & \multirow{10}{*}{ 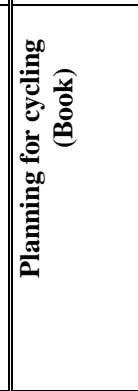 } & Network and continuity & $\checkmark$ & & \\
\hline & & Safer access routes & & & $\checkmark$ \\
\hline & & Clearance & $\checkmark$ & & \\
\hline & & Pathway/ street furniture & $\checkmark$ & & $\checkmark$ \\
\hline & & $\begin{array}{l}\text { Roadway width } 2.5 \text { meter } \\
\text { infrastructure for cyclists }\end{array}$ & $\checkmark$ & & $\checkmark$ \\
\hline & & Shared street & & $\checkmark$ & $\checkmark$ \\
\hline & & Cycle parking & $\checkmark$ & & $\checkmark$ \\
\hline & & Lighting & $\checkmark$ & & $\checkmark$ \\
\hline & & Directional signing & $\checkmark$ & & \\
\hline & & Making use of railways and parks & & $\checkmark$ & $\checkmark$ \\
\hline \multirow{6}{*}{ 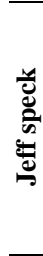 } & \multirow{6}{*}{ 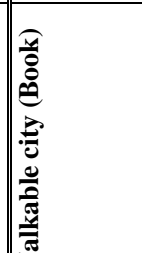 } & Mix the uses & & & $\checkmark$ \\
\hline & & Let transit work & $\checkmark$ & $\checkmark$ & \\
\hline & & $\begin{array}{c}\text { Get the parking right Protect the } \\
\text { pedestrians }\end{array}$ & & & $\checkmark$ \\
\hline & & Welcome bikes & & $\checkmark$ & \\
\hline & & Plant trees Provide enough & & & $\checkmark$ \\
\hline & & dimensions of sidewalks & & $\checkmark$ & \\
\hline \multirow{6}{*}{ 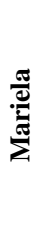 } & \multirow{6}{*}{ 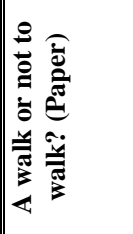 } & Sidewalk buffers, trees & & & $\checkmark$ \\
\hline & & Floor windows & $\checkmark$ & & \\
\hline & & Presence of mixed uses & & & \\
\hline & & Unique architecture & $\checkmark$ & & \\
\hline & & Public space & & & \\
\hline & & Sidewalk network & & $\checkmark$ & \\
\hline \multirow{9}{*}{ 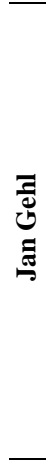 } & \multirow{9}{*}{ 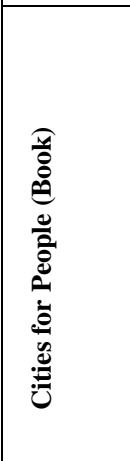 } & Human dimension & & & \\
\hline & & Compact, direct routes & & & \\
\hline & & Bicycle path on the right & & $\checkmark$ & \\
\hline & & Bicycle network & & $\checkmark$ & \\
\hline & & Avoid obstacles & & $\checkmark$ & \\
\hline & & Amenities at stations Human activity. & & & $\checkmark$ \\
\hline & & Rich façade & $\checkmark$ & & \\
\hline & & $\begin{array}{c}\text { Clear hierarchy of spaces Cycling lane } \\
\text { average is } 2.5 \mathrm{~m}\end{array}$ & & $\checkmark$ & \\
\hline & & Human activity. & $\checkmark$ & & \\
\hline \multirow{7}{*}{ 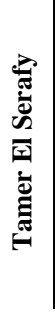 } & \multirow{7}{*}{ 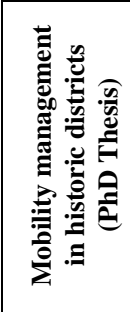 } & Interchange nodes & & $\checkmark$ & \\
\hline & & Car parking $\&$ pike sharing & $\checkmark$ & & $\checkmark$ \\
\hline & & Street furniture & $\checkmark$ & & $\checkmark$ \\
\hline & & Car free zone & & $\checkmark$ & \\
\hline & & Suitable paving materials & & $\checkmark$ & \\
\hline & & $\begin{array}{l}\text { Handicapped needs Pedestrian } \\
\text { crossings }\end{array}$ & & & \\
\hline & & $\begin{array}{l}\text { Avoid close vehicular to historic } \\
\text { buildings }\end{array}$ & $\checkmark$ & & \\
\hline
\end{tabular}

\section{CASE STUDY}

This research will discuss the case study of "El Galaa Street - Damietta city". The aim is to use cycling and walkability on this historical urban space to revive and make it more attractive for visitors. This section will be consisting of several steps including main urban characteristics of Damietta city, analyzing the existing situation of El Galaa street, Evaluations and Assessment of the urban space for successful walk able\& cycling districts, determining the main focal points using indicators that evaluating the efficiency of El Galaa street.

\section{A. Damietta city}

Damietta is a port and the capital of the Damietta Governorate in Egypt. It is located at the Damietta branch, a distributary of the Nile, (latitude $31^{\circ} 25^{\prime} \mathrm{N}$, longitude $31^{\circ} 49^{\prime} \mathrm{E}$ ). 15 kilometers $(9.3 \mathrm{mi})$ from the Mediterranean Sea, about 200 kilometers (120 mi) north of Cairo. [33]. Damietta city is considered one of Egypt's window on the coast of the Mediterranean Sea.

The historic urban areas in Damietta are accompanied with enormous economic, physical, environmental and social impacts and triggering huge challenges such as: urban sprawl, traffic problems, housing affordability issues, environmental degradation, noise and air pollution. El Kabas district is considered one of the main districts of the old city center of Damietta, it is a famous district for antiques and furniture. Since the past decades, the district was a mixture of different cultures and uses.

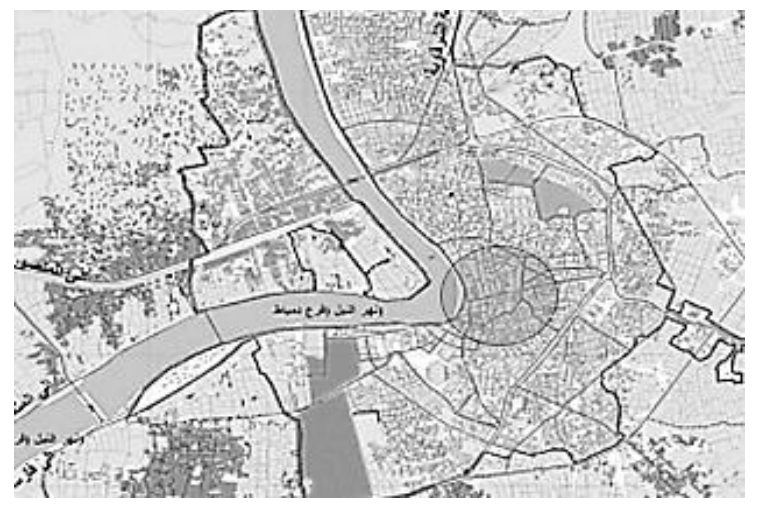

Fig. 3. El Galaa Street in Damietta city (Ref: [34] )

\section{B. Site Analysis}

This street is considered as a one of the main and oldest streets in the historic urban areas in Damietta as shown in figure (4)

The street has Economic and Functional value by playing a role in the daily economic life by Support of complementary activities related to basic activities in order to encouraging investment in such activities besides other commercial services, and Heritage value that indicates to the age of the site and its building which indicates to a historical event.

It is divided by three main intersections, starting by (1) el Saa Square; (2) El Kabas square and ends up with Bab El Hars street, as shown in figure $(5,6)$. at the part $(2)$ of the street is accommodating buildings with heights varying from 4 to 5 stories on the two side of the street. 


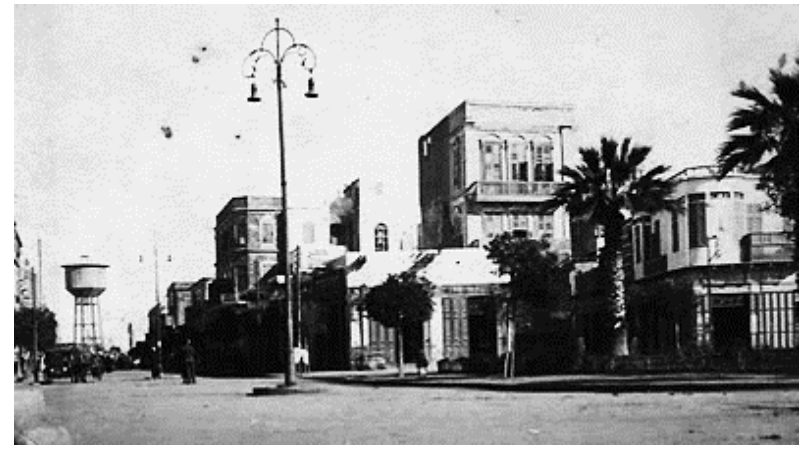

Fig. 4. .El Galaa Street in 1930 (Ref: [35] )

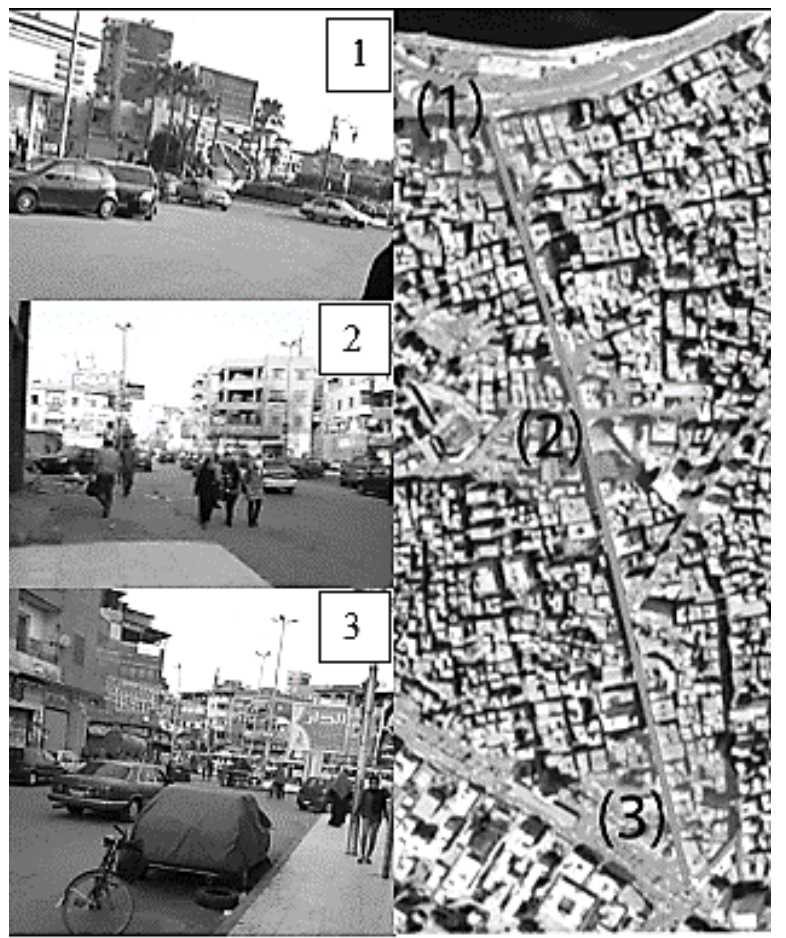

Figure 5. The urban fabric of El Galaa street with the three intersections (Ref: [36], Researcher,2018)

\section{Evaluation}

Hence, the following table (3) attempts to come up with a combined indicator that would evaluate the efficiency of historic streets for successful walking \& cycling.

Based on the definitions of walkability and the concluded criteria and indicators in an addition to interviewing pedestrian of El Galaa Street, they said that unfortunately the initiative did not meet residents, pedestrian cyclists' expectations and did not achieve the above-mentioned criteria and guidelines. For example, as for Attractiveness of walk is not interesting at all where the facades of the street are not rich and most of them are with horizontal lines with no first floor shops or mixed activities, as shown in figure (6). Moreover, safety; there are a lot of physical barriers in the street and sidewalks and no pedestrian crossings and many obstacles in the cycling lanes like holes and no levels separating cycling from cars. Also some cracks in sidewalks which end up with pedestrians using the street instead. Not to mention the fully occupied sidewalks with many obstacles such as lighting and advertisements posts, while the florists shops use the sidewalks for displays as shown in figure $(7,8 \& 9)$. The walk is also not comfortable where there is no presence of public space or street furniture, and no suitable car parking locations which led the community to park on the lane itself, as shown in figure (12). The landscaping is not pleasant and not designed.

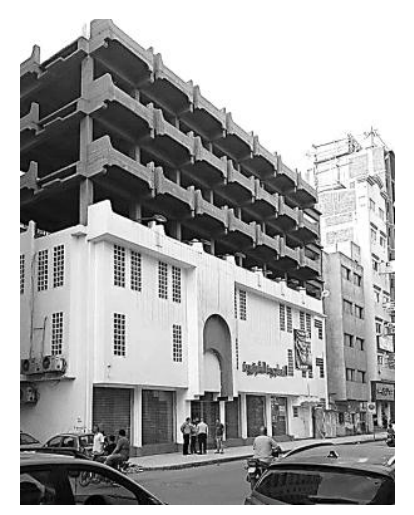

Figure. 6. The uninteresting facades of the street (Ref: Researcher,2018)

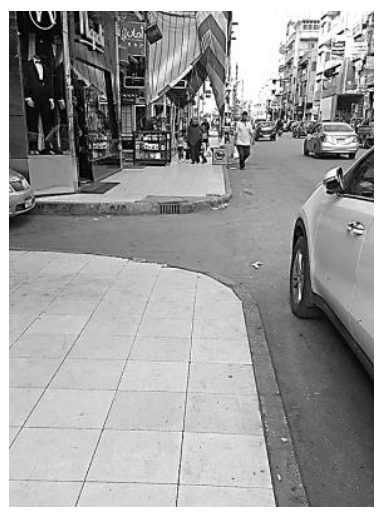

Figure. 8. pedestrians use the street instead of the fully occupied sidewalks (Ref: Researcher,2018)

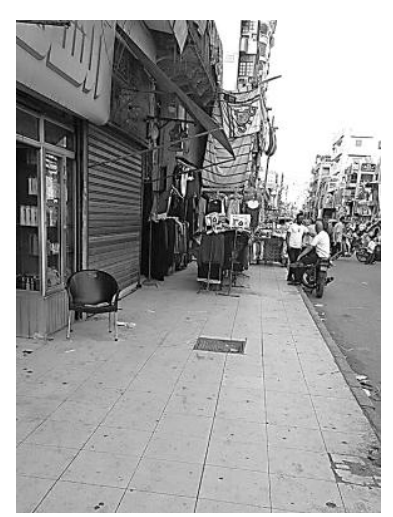

Figure. 7. shops use the sidewalks for display (Ref: Researcher,2018
Design and function did not follow the standards, as the width of the cycling lane is not determined to reach 2.5 meters .Also no consideration for handicapped needs, and no cycling parking or any street furniture as shown in figure (12)..The Economic \& useful aspect unfortunately was not enough studied very well, the pedestrian network links seamlessly, with interruptions and hazards, and no directional and lighting signage in the center of the street as shown in figure (11), Also as there is no continuity of the cycling lane and no networking or crossing lines between the three parts of the street as shown in figure (13). 
TABLE. 3.

CONDUCTED CRITERIA AND INDICATORS FOR EVALUATING THE EFFICIENCY OF EL GALAA STREET

\begin{tabular}{|c|c|c|c|c|c|c|c|c|}
\hline$\frac{n}{:=0}$ & 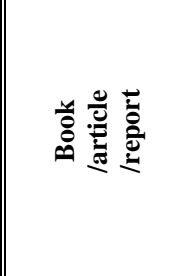 & $\begin{array}{l}\text { Indicators for successful walk able\& cycling } \\
\text { districts }\end{array}$ & 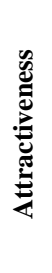 & 莺 & 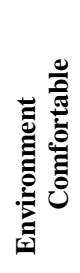 & 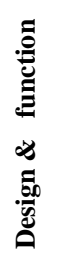 & 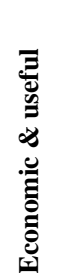 & 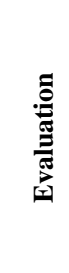 \\
\hline \multirow{10}{*}{ 冚 } & \multirow{10}{*}{ 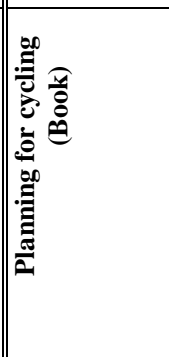 } & Network and continuity & $\sqrt{ }$ & & & & & good \\
\hline & & Safer access routes & & $\sqrt{ }$ & & & & poor \\
\hline & & Clearance & & $\sqrt{ }$ & & & & good \\
\hline & & Pathway/ street furniture & & & $\sqrt{ }$ & & & poor \\
\hline & & Roadway width 2.5 meter infrastructure for cyclists & & $\sqrt{ }$ & & & & good \\
\hline & & Shared street & & $\sqrt{ }$ & & & & poor \\
\hline & & Cycle parking & & $\sqrt{ }$ & & & & poor \\
\hline & & Lighting & & $\sqrt{ }$ & & & & good \\
\hline & & Directional signing & $\sqrt{ }$ & & & & & poor \\
\hline & & Making use of railways and parks & $\sqrt{ }$ & & & & $\sqrt{ }$ & good \\
\hline \multirow{6}{*}{ 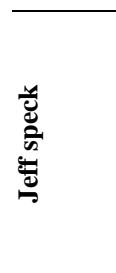 } & \multirow{6}{*}{ 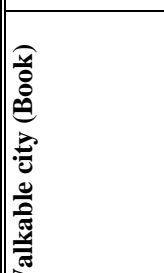 } & Mix the uses & & & & & $\sqrt{ }$ & good \\
\hline & & Let transit work & & & & & $\sqrt{ }$ & good \\
\hline & & Get the parking right Protect the pedestrians & & $\sqrt{ }$ & & & & poor \\
\hline & & Welcome bikes & & & $\sqrt{ }$ & & & poor \\
\hline & & Plant trees Provide enough & & & $\sqrt{ }$ & & & poor \\
\hline & & dimensions of sidewalks & & $\sqrt{ }$ & & & & poor \\
\hline \multirow{6}{*}{ 焉 } & \multirow{6}{*}{ 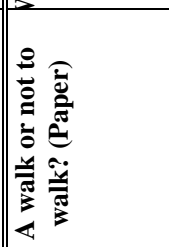 } & Sidewalk buffers, trees & & & $\sqrt{ }$ & & & poor \\
\hline & & Floor windows & $\sqrt{ }$ & & & & & poor \\
\hline & & Presence of mixed uses & & & & & $\sqrt{ }$ & good \\
\hline & & Unique architecture & $\sqrt{ }$ & & & & & good \\
\hline & & Public space & $\sqrt{ }$ & & & & & good \\
\hline & & Sidewalk network & & $\sqrt{ }$ & & & & good \\
\hline \multirow{9}{*}{ 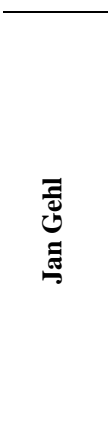 } & \multirow{9}{*}{ 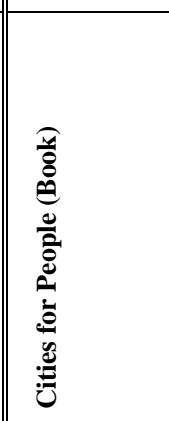 } & Human dimension & & & & $\sqrt{ }$ & & good \\
\hline & & Compact, direct routes & & $\sqrt{ }$ & & & & good \\
\hline & & Bicycle path on the right & & $\sqrt{ }$ & & $\sqrt{ }$ & & poor \\
\hline & & Bicycle network & & $\sqrt{ }$ & & & & poor \\
\hline & & Avoid obstacles & & $\sqrt{ }$ & & & & poor \\
\hline & & Amenities at stations Human activity. & & & $\sqrt{ }$ & & & good \\
\hline & & Rich façade & $\sqrt{ }$ & & & & & poor \\
\hline & & $\begin{array}{l}\text { Clear hierarchy of spaces Cycling lane average is } \\
2.5 \mathrm{~m}\end{array}$ & & $\sqrt{ }$ & & & & good \\
\hline & & Human activity. & $\sqrt{ }$ & & & & $\sqrt{ }$ & good \\
\hline \multirow{7}{*}{ 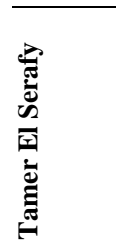 } & \multirow{7}{*}{ 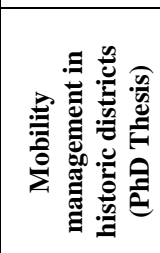 } & Interchange nodes & & $\sqrt{ }$ & & & & poor \\
\hline & & Car parking \& pike sharing & & & & & $\sqrt{ }$ & good \\
\hline & & Street furniture & & & $\sqrt{ }$ & $\sqrt{ }$ & & poor \\
\hline & & Car free zone & & $\sqrt{ }$ & & & & good \\
\hline & & Suitable paving materials & & $\sqrt{ }$ & & & & good \\
\hline & & Handicapped needs Pedestrian crossings & & $\sqrt{ }$ & & & & poor \\
\hline & & Avoid close vehicular to historic buildings & $\sqrt{ }$ & & & $\sqrt{ }$ & & poor \\
\hline
\end{tabular}




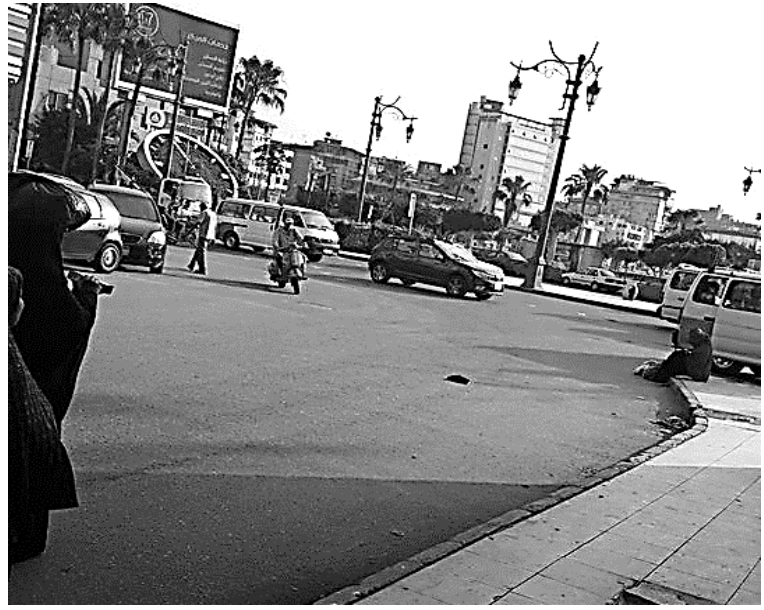

Figure. 11. There is no extra traffic cycling lighting signage (Ref: Researcher,2018)

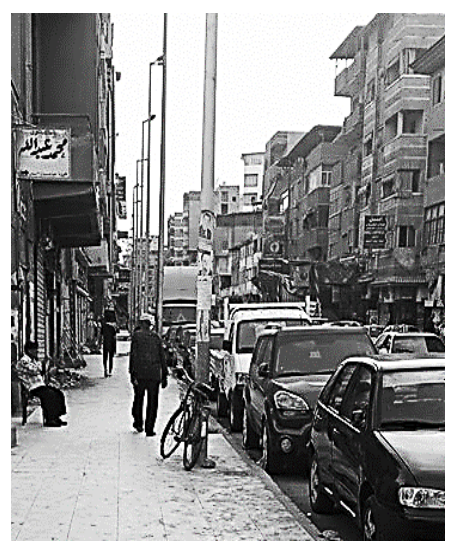

Figure. 12. The residents parked their private cars on the cycle lane (Ref: Researcher,2018)

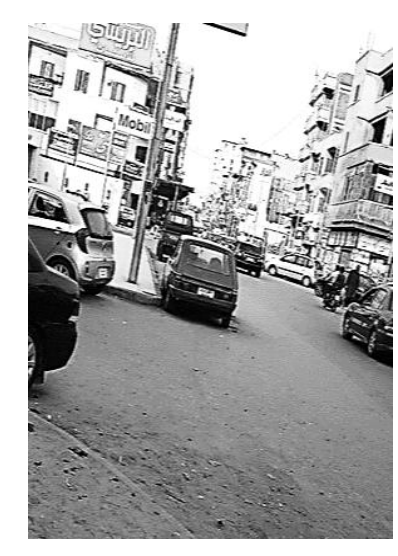

Figure. 13. There is no continuity and networking (Ref: Researcher,2018)

\section{CONCLUSION:}

Today and for most of the last century, we have taken for granted the idea that our streets are primarily zones for cars, parking, and for transporting our goods instead of zones for people to stroll, walk and cycling, however this has not been the case, decades ago. Walkability was increasingly valued for a variety of reasons; not only does pedestrian transportation reduce congestion and have low environmental impact; it has social, recreational value and above all revitalize the urban heritage from distortion. Places with higher walkability perform better commercially and have higher housing values, which is much needed in our historic districts to help to increase the awareness of historic urban values. While walking we see details in buildings and notice the activities in the street which is very much needed nowadays as the historic urban is in a huge risk. The different attributes associated with walkability and cycling worldwide have the capacity to improve attractiveness,

Safety, health comfortable and sustainability which decreases crime, and have an indirect effect on historic buildings values and the livability of the streets and historic urban. Accordingly, it is easy to apply cycling and walkability in the historic El Galaa Street, Damietta, in Egypt، using a guide manual and design criteria to follow while modifying walkability and enhancing cycling in historic urban areas. Putting into consideration, that choosing the street to be walkable and bikeable is not haphazardly, as not every existing street in historic areas could be easily revitalize to accommodate all different modes of transportation. In street most of the attributes and walkability needs are not applied, yet it failed to meet the cyclists and pedestrian's expectations based on a global guidelines and standards. This inefficiency reveals the unawareness of the walkability needs whether by the government or by street inhabitance.

The choice of El Galaa Street as a start for urban revitalization has these results for evaluating the efficiency of cycling \& walkability:

- It should be a more interesting street with more vertical and interesting old facades

- It should have a mixed land uses with more activities.

- Pedestrian and cycling amenities should have been available to help pedestrians enjoy their walk and feel more comfortable.

- The pavements, Street furniture, the obstacles in the walkways and cycling lane, should have been enhanced in a comfort and safer way.

- The cycling path should follow the international standards with minimum $1.7 \mathrm{~cm}$ width.

- Achieve the human dimension, to provide a general sense of protection and safety.

- Consult people in the area early on the changes that will be made before the plans are drawn up and approved.

- The need to renew the sources and methods of financial grants for projects to improve and develop historic areas so that the mixed-use projects programs look attractive to investors and donors.

\section{REFERENCES}

[1]. Fishman, E. (2016). Cycling as transport. Routledge, 1-8.

[2]. Macclintock, H. (2002). Planning for cycling: principles, practice and solutions for urban planners. England: CRC Press and Woodhead publishing Ltd.

[3]. Speck, J. (2013, October 15). America Has So Many Problems. Walkability Solves Most of Them. Retrieved August 10, 2016, from STREETSBLOG USA:

http://usa.streetsblog.org/2013/10/15/jeff-speck-america-has-somany-problems- walkabilitysolves- most-of-them/

[4]. Walkable, B. F. (1998). Creating Walkable Communities. Washington: Mid-America Regional Council(MARC).

[5]. Speck, J. (2012). Walkable City: How Downtown Can Save America, One Step at a Time.USA: Farrar, Straus and Giroux.1 Approaches and lessons for enhancing walkability.

[6]. Kafafy, M. R. (2014). Approaches and lessons for enhancing walkability in cities: a landscape conceptual solution for Talaat Harb Street,Cairo. International Journal of Education and Research, 301-322.

[7]. Macclintock, H. (2002). Planning for cycling: principles, practice and solutions for urban planners. England: CRC Press and 
Woodhead publishing Ltd.

[8]. Speck, J. (2012). Walkable City: How Downtown Can Save America, One Step at a Time.USA: Farrar, Straus and Giroux.1 Approaches and lessons for enhancing walkability

[9]. MARIELA A. ALFONZO. (2005). TO WALK OR NOT TO WALK?The Hierarchy of Walking Needs. ENVIRONMENT AND BEHAVIOR, 808-836.

[10]. Gehl, J. (2010). Cities for people. Washington, DC: Island press.

[11]. ElSerafy, T. (2017). MOBILITY MANAGEMENT IN HISTORIC DISTRICTS. Cairo: Cairo University.

[12]. El-Dorghamy, A. (2015). Fuel Economy and CO2 Emissions of Light-Duty Vehicles in Egypt. Cairo: Centre for Environment and Development in the Arab Region and Europe (CEDARE).

[13]. El-Dorghamy, A. (2015). Fuel Economy and CO2 Emissions of Light-Duty Vehicles in Egypt. Cairo: Centre for Environment and Development in the Arab Region and Europe (CEDARE).

[14]. USAID 2004: The Cairo Air Improvement Project: Helping Millions Live Healthier Lives, Final Report, USAID, March 2004.

[15]. United Nations Framework Convention for Climate Change (2009): Egypt Vehicle Scrapping and Recycling Program, Version 1.0, Small-scale CDM programme of activities design document form, retrieved from:

https://cdm.unfccc.int/ProgrammeOfActivities/poa_db/JMC6IEO PXNUSTA2Q78DFZ4 GW9LHKV1/view

[16]. Shoup, D. (2005). The High cost of free parking. Chicago: Planner Press.

[17]. Mohareb, Nabil Ibrahim (2003),"The Role of Urban Spaces in The Revitalization of Historic Sites", Master

Thesis, Faculty of Engineering, University of Alexandria, Page (2-2)

[18]. Tiesdell, Steven, Taner Oc and Tim Health (1998),"Revitalizing Historic Urban Quarters", Oxford: Architecture Press.p.13.

[19]. Lynch,Kevin (1996),"City Sense and City Design ",Ed.Tridib Banerjee \& Micheal Southworth, London ,England:The MIT Press .

[20]. Goodland Robert, (1987), "Neoclassical Economic and Principles of Sustainable Development", Ecological Modeling, Vol. 38, P.36.

[21]. Vileniske, I.G., \& Urbonas, v. (2014). Urban regeneration in the context of post - Soviet transformation: Lithuanian experience.
Journal of cultural Heritage, 1(2), 1-7.

[22]. Antony G. Bigio (2010): "The Urban Rehabilitation of Midnas", Urban Development Series, Knowledge papers, the World Bank, Urban Development\& local Government, No.9, p. 17.

[23]. Tiesdell, S., Oc, T., Heath, T. (1996), Revitalizing Historic Urban Quarters, Oxford: Architectural Press.

[24]. Antony G. Bigio (2010): "The Urban Rehabilitation of Midnas", Urban Development Series, Knowledge papers, the World Bank, Urban Development\& local Government, No.9, p. 17.

[25]. David Elliott \&Marissa Silverman \&Wayne Bowman (2016): " Artistic Citizenship: Artistry, Social Responsibility, and Ethical Praxis", Oxford University Press, U.S.A.

[26]. Francis Tibbalds (2001): "Making People-Friendly Towns: Improving the Public Environment in Towns and Cities", Longman Group UK, Ltd.

[27]. Jin Alexander Tsuchiya (2013): "An Examination of Policy Options along the Welton Street Urban Corridor", Institute for Public Policy Studies, University of Denver.

[28]. Speck, J. (2013, October 15). America Has So Many Problems. Walkability Solves Most of Them. Retrieved August 10, 2016, from STREETSBLOG USA:

http://usa.streetsblog.org/2013/10/15/jeff-speck-america-has-somany-problems- walkabilitysolves- most-of-them/

[29]. Araby, K. E. (2013). Urban Transport Issues in Egypt. International Symposium Mobility and Infrastructure. El Gouna, $1-12$.

[30]. David Elliott \&Marissa Silverman \&Wayne Bowman (2016): " Artistic Citizenship: Artistry, Social Responsibility, and Ethical Praxis", Oxford University Press, U.S.A.

[31]. Steven Tiesdell, Taner OC\& Tim Heath (1996): "Revitalizing Historic Urban Quarters", Architecture Press, Oxford, Britain, p. 21, 203, 208, 209.

[32]. Marichela Sepe (2013): "A Dynamic Method and Interactive Software to Monitor and Design Place Identity", Chapter 20.

[33]. http://en.wikipedia.org/wiki/Damietta (26-06-2018)

[34]. https://www.google.com/earth/ (25-06-2018)

[35]. http://damayta.blogspot.com.eg/ (26-06-2018)

[36]. https://www.google.com/earth/ (25-06-2018) 